\title{
COPHYLOGENETIC ANALYSES OF TRACHYMYRMEX ANT-FUNGAL SPECIFICITY: 'ONE TO ONE WITH SOME EXCEPTIONS'
}

\author{
Katherine Beigel $^{1}$, Alix Matthews ${ }^{2}$, Katrin Kellner ${ }^{3}$, Christine Pawlik ${ }^{1}$, Matthew \\ Greenwold $^{1}$, and Jon Seal ${ }^{1}$ \\ ${ }^{1}$ University of Texas at Tyler \\ ${ }^{2}$ Arkansas State University \\ ${ }^{3}$ University of Texas at Austin
}

May 27, 2021

\begin{abstract}
Over the past few decades, large-scale phylogenetic analyses of fungus-gardening ants and their symbiotic fungi have depicted strong concordance among major clades of ants and their symbiotic fungi, yet within clades, fungus sharing is somewhat widespread among unrelated ant lineages. These symbioses are thought to be explained by a diffuse coevolution model within major clades. Understanding horizontal exchange within clades has been limited by conventional genetic markers that lack both interspecific and geographic variation. To examine whether reports of horizontal exchange was indeed symbiont sharing or an issue of employing relatively uninformative molecular markers, samples of Trachymyrmex arizonensis and Trachymyrmex pomonae and their fungi were collected from native populations in Arizona and genotyped using conventional marker genes and genome-wide single nucleotide polymorphisms (SNPs). Conventional markers of the fungal symbionts generally exhibited cophylogenetic patterns that were consistent with some symbiont sharing, but most fungal clades had low support. SNP analysis, in contrast, indicated that each ant species exhibited fidelity to its own fungal subclade with only one instance of a colony growing a fungus that was otherwise associated with a different ant species. This evidence supports a pattern of codivergence between Trachymyrmex species and their fungi, and thus a diffuse coevolutionary model may not accurately predict symbiont exchange. These results suggest that fungal sharing across host species in these symbioses may be less extensive than previously thought.
\end{abstract}

\section{Hosted file}

Beigel_etal_2021_ Specificity of ants and their fungi_final.docx available at https: //authorea.com/users/416140/articles/523796-cophylogenetic-analyses-of-trachymyrmexant-fungal-specificity-one-to-one-with-some-exceptions 